BMJ Open

Sport \&

Exercise

Medicine

\title{
No pain no gain: a survey of use of healthcare and reasons not to seek healthcare by Norwegian climbers with chronic injuries
}

\author{
Gudmund Grønhaug, ${ }^{\circledR}$ Atle Saeterbakken
}

\begin{abstract}
To cite: Grønhaug G, Saeterbakken A. No pain no gain: a survey of use of healthcare and reasons not to seek healthcare by Norwegian climbers with chronic injuries. BMJ Open Sport \& Exercise Medicine 2019;5:e000513. doi:10.1136/ bmjsem-2019-000513
\end{abstract}

Accepted 23 April 2019

\section{Check for updates}

(c) Author(s) (or their employer(s)) 2019. Re-use permitted under CC BY-NC. No commercial re-use. See rights and permissions. Published by BMJ.

Education, arts and sports, Western Norway University of Applied Sciences, Sogndal, Norway

Correspondence to Gudmund Grønhaug; groenhaug@gmail.com

\section{ABSTRACT}

Objectives To assess the use of healthcare, and reasons not to seek healthcare, by climbers with a chronic injury.

Method Retrospective survey.

Setting Web-based questionnaire.

Participants 667 active climbers (385 with chronic injuries).

Outcome measure Use of healthcare (including reasons not to seek healthcare if the patient was not attended by health professionals), performance level in sport climbing, onset of a climbing-related injury, site of injury, preferred style of climbing and gender differences.

Result Of the 667 respondents, 385 had experienced a chronic injury in the past 6 months. Climbers with a chronic injury are reluctant to seek healthcare, and male climbers are less likely to seek healthcare than female climbers. The two most frequent reasons not to seek healthcare were: (1) an assumption that the injury was not serious enough $(70 \%)$ and (2) a belief that a health professional could not help $(60 \%)$. Only one in five of the climbers with a finger injury sought healthcare. The more experienced climbers were less likely to seek healthcare than recreational climbers.

Conclusion Use of healthcare among climbers with a chronic injury is limited and injured climbers self-assess the injury before seeking medical aid. Experience is a strong predictor for not seeking healthcare after an injury. These findings open up the possibility that some of those who do not seek healthcare after self-assessing the injury are underestimating the seriousness of the injury due to lack of confidence in the health professionals' abilities to help treating chronic climbing related injuries.

\section{INTRODUCTION}

Competitive sport climbing consists of three major disciplines: lead climbing, bouldering and speed climbing. In the upcoming Tokyo 2020 Olympics, climbing will be included for the first time with one medal for a combined result from all three disciplines. Climbing has evolved from a small, insignificant activity, attracting few to a sport that now raises headlines in international media. ${ }^{1}$ Organised sport activities, as a whole, are on the rise and climbing is one of the activities that is

\section{Key messages}

What was known?

- Climbers as a group are reluctant to seek healthcare.

- Injuries in climbing are often not assessed by health professionals with expertise in climbing.

What is new?

- There are differences in the use of healthcare based on gender and level of experience.

- Most climbers self-assess their injury as not too serious and keep climbing.

- Climbers do not have faith in health professionals knowledge on how to treat climbing-related chronic injuries.

growing the most. ${ }^{2}$ There has been a rapid development in indoor climbing facilities, with climbing gyms being built in all major cities. In Norway, the number of organised climbers has doubled between 2006 and $2016 .^{3}$ One consequence of the increasing number of climbers is that more people are at risk of developing climbing-related chronic injuries. ${ }^{4-8}$

With an assumed increase in the number of climbers with injuries, both acute and chronic, the education of health personnel and trainers is important. Up-to-date knowledge of climbing injuries and climbers' views on seeking healthcare is needed to ensure that climbers with an injury are assessed properly and given the help needed to recover. However, most of the research on climbing-related injuries combine acute injuries and chronic injuries, ${ }^{9-12}$ and knowledge of climbers' beliefs about the value of healthcare is scarce. ${ }^{12}$ Although most people engaged in sports operate at moderate levels of intensity, most of the research on the use of sports medicine is based on studies assessing team sports and elite-level subjects. ${ }^{13} 14$

In most sports, the onset of an injury differs for acute and chronic injuries. Athletes experiencing pain when training are suggested to 
tentatively self-diagnose and distinguish between performance pain and injury pain. ${ }^{15}$ Acute injuries in climbing tend to be a high-energy trauma demanding an obvious reason to seek medical aid, ${ }^{16-18}$ while most chronic injuries are injuries that develop gradually over time and which may cause mild pain over a number of weeks before it is perceived as an injury. Nevertheless, most studies on climbing-related injuries do not take into consideration whether the injury is chronic or acute. ${ }^{9} 1019$

Although previous studies on climbing injuries have revealed that chronic injuries are more prevalent than acute injuries, ${ }^{720}$ the literature on chronic climbing injuries has been limited with a focus on a single diagnosis based on a limited number of subjects. ${ }^{21}{ }^{22}$ Recently, more studies have focused on the epidemiology of climbing injuries. ${ }^{10} 11$ 23-25 These studies conclude that fingers, shoulders and elbows are the most common sites of injury for all climbers regardless of level of climbing and gender. ${ }^{924}$ However, there seems to be gender differences regarding the distribution of climbing injuries; female respondents tend to have more injuries in their wrists and ankles than the male respondents, who have a higher presenceof elbow and finger injuries. ${ }^{25}$

Previous research on the use of healthcare by climbers has not separated chronic and acute injuries, assessed gender differences or differences in the view on seeking healthcare based on performance level. Hence, the aim of this study is to assess the use of healthcare, and reasons not to seek healthcare, by climbers with a chronic injury. A secondary aim is to assess the influence of gender and climbing performance on the use of healthcare and reasons not to seek healthcare.

\section{METHODS}

Design

Cross-sectional anonymous web-based survey. Apart from highlighting the survey as a survey on chronic injuries in climbing. No further definition or operationalisation of chronic injuries was given.

The Norwegian Climbing Federation helped promote the survey via their national website. Furthermore, the survey was promoted by a Norwegian national climbing magazine in a web article as well as via shared Facebook posts and other web pages at the time of inclusion. The questionnaire was open for respondents from $21 \mathrm{March}$ 2017 to 2 May 2017. The questionnaire was only available in Norwegian.

\section{Sociodemographics, experience level and other training}

The questionnaire included questions about age $(\leq 10$, 11-15, 16-20, 21-25, 26-30, 31-40, 41-50, 51-60, >60), gender and the highest achieved grade during the last 6 months for a prepractised climb (redpoint) in both bouldering and lead climbing. Subsequently, experience levels (recreational, intermediate, experienced, elite and international elite) were grouped as suggested in Grønhaug and Norberg's 2016 study (9). There were no respondents in the international elite group. Respondents were also asked a yes/no question on whether or not they took part in other sports than climbing.

\section{Self-perceived injuries and time out of training}

The questionnaire included two questions on injuries:

During the past 6 months, have you experienced climbing-related chronic injuries? (yes, no). If 'yes' was ticked, a follow-up question was asked: Where did you have an injury? (toe, foot/ankle, calf, knee, thigh, hip, lower back, shoulder, elbow, wrist, fingers, neck, head).

The respondents were asked two questions on time away from training:

Did you stop training? (yes, trained at lower level, no). If 'yes' was ticked, a follow-up question was asked: How long did you stay out of training? (did not stop training, $>1$ week, 1 week, 2-4 weeks, 1-3 months, 4-6 months, >6 months).

Assessment of healthcare was based on two questions: Did you seek healthcare? (yes, no). If "no" was ticked off, a follow up question was asked: Why did you not seek healthcare? (the injury was not serious enough, did not have the time, treated it myself, do not think health professionals know enough about climbing-related injuries, have friends who sought healthcare and it did not help, a friend helped me out). For this latter question, respondent could select more than one answer.

\section{Statistics}

SPSS V.25 for Windows was used to perform descriptive statistics and Pearson's $\chi^{2}$ was used to assess systematic differences relating to gender and climbing performance levels. The results are presented with Cramer's V $(\varphi)$ to report the effect size. Effect sizes are set according to Rea and RA's 2014 study $(0.10$ to $<0.20=$ weak, 0.20 to $<0.40=$ moderate, 0.40 to $<60=$ relatively strong). ${ }^{26}$ Level of significance is set to 0.05 .

\section{RESULTS}

\section{Participant characteristics}

The main survey received 667 responses. ${ }^{25}$ A total of 385 respondents from this survey reported that they had experienced a chronic climbing-related injury in the past 6 months (see table 1). A majority of these respondents were male $(75 \%)$. Most of the respondents practised other sports $(80.3 \%)$ and operated in the intermediate levels of climbing $(49.3 \%)$. The most common sites of injury reported were fingers $(41.6 \%)$, shoulders $(19.5 \%)$ and elbows $(17.4 \%)$. After the onset of an injury, most respondents either trained at a lower level $(66 \%)$ or stopped training $(24.7 \%)$. Only $9.4 \%$ trained as usual.

\section{Use of healthcare among respondents}

Gender is significantly associated with seeking healthcare. $41.7 \%$ of the female respondents sought healthcare versus $27.3 \%$ of the male respondents $\left(\chi^{2}=0.006\right.$, Cramer's $\mathrm{V} \varphi=0.125$ (see table 2).

\section{Other sports than climbing}

There was a non-significant higher proportion of respondents who declined to seek medical aid in the group of 
Table 1 Respondent characteristics: respondents reporting a chronic injury in the past 6 months

\begin{tabular}{lc}
\hline Questionnaire particulars & $\begin{array}{l}\text { All respondents } \\
\mathbf{N}=\mathbf{3 8 5}\end{array}$ \\
\hline Gender & \\
\hline Male & 289 \\
Female & 96 \\
\hline Are you doing any other training than climbing? \\
\hline Yes & 309 \\
\hline No & 76 \\
\hline Level of performance & 74 \\
\hline Recreational & 190 \\
\hline Intermediate & 109 \\
Experienced & 12 \\
\hline Elite & \\
\hline
\end{tabular}

Where did you have an injury?

\begin{tabular}{|lr|}
\hline Lower extremities & 42 \\
\hline Lower back, neck, head, hip & 17 \\
\hline Shoulder & 75 \\
\hline Elbow & 67 \\
\hline Wrist & 24 \\
\hline Fingers & 160 \\
\hline Did you seek healthcare? & \\
\hline Yes & 119 \\
\hline No & 266 \\
\hline
\end{tabular}

Did you stop training?

\begin{tabular}{|rr}
\hline Yes & 95 \\
\hline No & 36 \\
\hline Trained at lower level & 254 \\
\hline How long did you stop training? \\
\hline Did not stop training & 290 \\
\hline$<1$ week & 7 \\
\hline 1 week & 8 \\
\hline 2-4 weeks & 39 \\
\hline 1-3 months & 31 \\
\hline $4-6$ months & 4 \\
\hline$>6$ months & 6 \\
\hline
\end{tabular}

respondents that did not do other sports than climbing $(76.3 \%$ vs $67.3 \%) \quad\left(\chi^{2}=0.287\right.$, Cramer's V $\left.\varphi=0.061\right)$.

\section{Level of performance}

Level of performance is associated with seeking healthcare $\left(\chi^{2}=0.009\right.$, Cramer's V $\left.\varphi=0.114\right)$.

\section{Site of injury}

Site of injury is significantly associated with seeking healthcare $\left(\chi^{2}=0.000\right.$, Cramer's V $\left.\varphi=0.755\right)$, and climbers with finger injuries are the most reluctant to seek medical help $(87.5 \%)$.

\section{Stopped training}

There is a significant association between seeking healthcare and stopping the training $\left(\chi^{2}=0.000\right.$, Cramer's V $\varphi=0.713)$, and most respondents either stop training or train at a lower level when injured $(66 \%)$.

Time out of training is also significantly associated with seeking healthcare $\left(\chi^{2}=0.000\right.$, Cramer's V $\left.\varphi=0.327\right)$.

\section{Reasons for not seeking healthcare, male and female compared}

Apart from more male respondents treating their injury themselves $\left(\chi^{2}=0.073\right.$, Cramer's V $\left.\varphi=0.110\right)$, there were no gender differences in the reported reasons not to seek medical aid (see table 3 ).

\section{Reasons for not seeking healthcare assessed for different levels of performance}

The more experienced have less faith in the competence of health professionals regarding climbing-related injuries $\left(\chi^{2}=.00\right)$, (see table 4$)$. Still, the trend of lack of belief in healthcare competence is of a moderate alpha level (Cramer's V $\varphi=0.207$ ).

\section{DISCUSSION}

In the present study, more than half of the responding climbers had experienced a chronic injury in the previous 6 months. Most of these were reluctant to seek healthcare, and male climbers were more reluctant to seek healthcare than female climbers. Although finger injuries were the most common climbing-related chronic injury, ${ }^{9}{ }^{25}$ those who sustained an injury to the fingers were the most reluctant to seek healthcare. The greater the experience of the climber, the stronger was the lack of faith in the likelihood that the health service would add value-be able to treat the condition.

The findings in the present study of $57 \%$ of the respondents having sustained a chronic injury in the past 6 months extend findings from previous studies. ${ }^{9} 10$ 22-24 The proportion of climbers reporting an injury in the present study is probably overestimated due to the self-selection of respondents. Furthermore, some of the injuries reported in this survey may not qualify as chronic injuries, but rather were acute injuries or just some pain. Injuries reported to require 1 week or less to cure with continued training was probably not a chronic injury. Making a correct diagnosis based on pain sensation is often difficult even for health personnel and may not be possible for the person experiencing the pain. ${ }^{27} 28$

Previous studies examining the use of healthcare by climbers reported that $36 \%-38 \%$ of the injured climbers sought medical help for their injuries. ${ }^{10} 202930$ These studies reported all injuries, regardless of the nature of the injury: acute or chronic. Acute injuries in climbing differ from chronic injuries in so many aspects that it is reasonable to believe that the use of healthcare also differs. Still, the results of the previous studies are supported by the present study. 
Table 2 Assessment of use of healthcare for chronic injuries in climbing

\begin{tabular}{|c|c|c|c|c|c|}
\hline Variable & $\begin{array}{l}\text { Sought } \\
\text { healthcare } n=119\end{array}$ & $\begin{array}{l}\text { Did not seek } \\
\text { healthcare } n=266\end{array}$ & $\begin{array}{l}\% \text { that did not } \\
\text { seek healthcare }\end{array}$ & $\chi^{2}$ & Cramer's V ( $\phi)$ \\
\hline Gender & & & & 0.006 & 0.125 \\
\hline Male & 79 & 210 & 72.7 & & \\
\hline Female & 40 & 56 & 58.3 & & \\
\hline \multicolumn{3}{|c|}{ Are you doing any other sports than climbing? } & & 0.287 & 0.061 \\
\hline Yes & 101 & 208 & 67.3 & & \\
\hline No & 18 & 58 & 76.3 & & \\
\hline \multicolumn{2}{|l|}{ Level of performance } & & & 0.009 & 0.114 \\
\hline Recreational & 35 & 39 & 52.7 & & \\
\hline Intermediate & 50 & 140 & 73.7 & & \\
\hline Experienced & 29 & 80 & 73.4 & & \\
\hline Elite & 5 & 7 & 58.3 & & \\
\hline \multicolumn{2}{|l|}{ Site of injury } & & & 0.000 & 0.755 \\
\hline Lower extremities & 21 & 21 & 50 & & \\
\hline $\begin{array}{l}\text { Lower back, neck, } \\
\text { head, hip }\end{array}$ & 7 & 10 & 58.8 & & \\
\hline Shoulder & 41 & 34 & 45.3 & & \\
\hline Elbow & 22 & 45 & 67.2 & & \\
\hline Wrist & 8 & 16 & 66.7 & & \\
\hline Fingers & 20 & 140 & 87.5 & & \\
\hline \multicolumn{3}{|c|}{ After the injury did you stop training? } & & 0.000 & 0.713 \\
\hline Yes & 39 & 56 & 58.9 & & \\
\hline Train at lower level & 70 & 184 & 72.4 & & \\
\hline No & 10 & 26 & 72.2 & & \\
\hline \multicolumn{3}{|c|}{ How long did you stop training? } & & 0.000 & 0.327 \\
\hline Did not stop training & 80 & 210 & 72.4 & & \\
\hline$<1$ week & 0 & 7 & 100 & & \\
\hline 1 weeks & 1 & 7 & 87.5 & & \\
\hline 2-4 weeks & 10 & 29 & 74.4 & & \\
\hline $1-3$ months & 19 & 12 & 38.7 & & \\
\hline 4-6 months & 4 & 0 & 0 & & \\
\hline$>6$ months & 5 & 1 & 16.7 & & \\
\hline
\end{tabular}

Differentiated for those who sought healthcare $(n=119)$, those who did not seek healthcare $(n=266)$ and \% that did not seek healthcare.

Presented with $\chi^{2}$ and Cramer's $V$ to examine the relations between the variables and seeking healthcare.

When $70 \%$ of the respondents who report to have sustained an injury by self-assessment, also report that the injury is not serious enough to seek healthcare, it raises a question of whether or not self-reported injuries are a reliable source of information. There is a possibility that many of those who report to have sustained an injury just experienced some pain. Importantly, pain is not necessarily caused by an injury. The survey did not quantify the level of pain (ie, using a Visual Analogue Scale) and some of the injuries reported would possibly not be classified as an injury by a health professional. No matter what the reasons were for not seeking healthcare, self-diagnosing, self-treatment and self-medication involve great risk. All self-treatment is insecure, ${ }^{28}$ and the risk of maltreatment is more likely as diagnostics are more often wrong. ${ }^{15}$ Injuries to the fingers are the most common injury and also the most difficult to diagnose correctly. ${ }^{22}{ }^{27}$ The present findings demonstrate that respondents with a finger injury are least likely to use health professionals to help treating their injuries. Because this group is also more inclined to perform self-treatment, there is a potential risk of future re-injuries and sequelae. The differentiation of pain and injuries may to some degree explain why those who sought healthcare were out of training for a longer time than the ones who did not seek healthcare (table 1). This is supported by previous research that found climbers who experienced a severe injury were the ones who sought healthcare. ${ }^{920}$ 
Table 3 Reasons for not seeking healthcare

\begin{tabular}{|c|c|c|c|c|c|}
\hline Responses & All n=266 (\%) & $\begin{array}{l}\text { Male } \mathrm{n}=\mathbf{2 1 0} \\
(\%)\end{array}$ & $\begin{array}{l}\text { Female } n=56 \\
(\%)\end{array}$ & $\chi^{2}$ & Cramer's V $(\phi)$ \\
\hline The injury was not serious enough & $187(70.3)$ & $148(70.5)$ & 39 (69.6) & 0.903 & 0.007 \\
\hline Did not have the time & $23(8.6)$ & $17(8.1)$ & $6(10.7)$ & 0.536 & 0.038 \\
\hline Treated it myself & $78(29.3)$ & 67 (31.9) & $11(19.6)$ & 0.073 & 0.110 \\
\hline $\begin{array}{l}\text { Do not think health professionals know enough } \\
\text { about climbing-related injuries }\end{array}$ & $63(23.7)$ & $50(23.8)$ & $13(23.2)$ & 0.926 & 0.006 \\
\hline $\begin{array}{l}\text { Have friends who tried healthcare, and it did not } \\
\text { help }\end{array}$ & $23(8.6)$ & $19(9)$ & $4(7.1)$ & 0.652 & 0.028 \\
\hline A friend helped me out & $20(7.5)$ & $16(7.6)$ & $4(7.1)$ & 0.904 & 0.007 \\
\hline
\end{tabular}

The results are presented for all participants and subgrouped male and female (injured climbers $\mathrm{n}$ and \%).

Although the injury mechanisms may differ in climbing compared with other sports, few climbing-specific injuries have been reported. ${ }^{22} 31$ Still, climbers are reluctant to use professional healthcare, and the groups least likely to seek healthcare are male climbers, climbers with a finger injury and experienced and elite climbers (table 2). Although gender is significantly associated with the use of healthcare, gender is less predictive of the belief in the competence in healthcare than climbing experience level (tables 3 and 4).

The climbing experience level shows a significant association with the belief in healthcare. This contradicts findings on healthcare utilisation in general society where gender is a strong predictor for healthcare utilisation. ${ }^{32}{ }^{33}$ Whether this finding is pointing towards a culture in climbing where climbers listen more to other climbers than healthcare personnel $^{1134}$ or if this disbelief in healthcare exists in other individual sports as well, is not known.

More experienced climbers tend to train the next generations. It is known from previous research that injuries among younger climbers are on the rise, and one of the climbing injuries on the rise is stress fractures to the epiphysial plates in the fingers. ${ }^{35} 36$ This is a highly specific finger injury that needs proper treatment. Given that climbers with injuries in the fingers rarely visit health services, this situation could potentially develop into a problem and needs to be properly addressed by the national organisations and the sports medicine community. Still, in a recent publication, it is shown that the use of campus board (feetless climbing on small edges) and use of weighted hangs on small edges is in regular use in organized training in France ${ }^{37}$ From the previous research, we know that the intermediate and experienced climbers are those who most often sustain a chronic injury. ${ }^{25}$ This present study found that these groups were also the most reluctant to seek healthcare when they were injured (table 4).

As this study is based on a cross-sectional survey, it is not known if the respondents who sought healthcare got the help they needed, or if those that returned to climbing sooner sustained new injuries or prolonged their injury in other ways. Algorithms for return to sport after injuries have been made for other sports. ${ }^{6}$ An initiative for making an algorithm for the diagnostics and treatment of finger injuries in climbers has been created, but more research and refinement is needed before it is ready for use. ${ }^{27}$

\section{Strengths and limitations}

The time of the survey may have had an impact on reported injuries. The survey was open from 21 March 2017 to 2May 2017, a period where most of the climbers

Table 4 Reasons for not seeking healthcare

\begin{tabular}{|c|c|c|c|c|c|c|}
\hline Responses & $\begin{array}{l}\text { Recreational } \\
\mathrm{n}=39(\%)\end{array}$ & $\begin{array}{l}\text { Intermediate } \\
\mathrm{n}=140(\%)\end{array}$ & $\begin{array}{l}\text { Experienced } \\
\mathrm{n}=80(\%)\end{array}$ & $\begin{array}{l}\text { Elite } \\
\mathrm{n}=7(\%)\end{array}$ & $\chi^{2}$ & $\begin{array}{l}\text { Cramer's V } \\
(\phi)\end{array}$ \\
\hline $\begin{array}{l}\text { The injury was not serious } \\
\text { enough }\end{array}$ & $30(76.9)$ & $100(71.4)$ & 57 (71.3) & $4(57.1)$ & 0.549 & 0.089 \\
\hline Did not have the time & $2(5.1)$ & $15(10.7)$ & $6(7.5)$ & 2 (28.6) & 0.101 & 0.153 \\
\hline Treated it myself & $10(25.6)$ & $39(27.9)$ & $29(36.3)$ & $4(57.1)$ & 0.368 & 0.109 \\
\hline $\begin{array}{l}\text { Do not think health } \\
\text { professionals know enough } \\
\text { about climbing-related injuries }\end{array}$ & $6(15.4)$ & $30(21.4)$ & $27(33.4)$ & $5(71.4)$ & 0.010 & 0.207 \\
\hline $\begin{array}{l}\text { Have friends who tried } \\
\text { healthcare and it did not help }\end{array}$ & $2(5.1)$ & $14(10)$ & $14(17.5)$ & 0 & 0.660 & 0.078 \\
\hline A friend helped me out & $1(2.6)$ & $10(7.1)$ & $9(11.3)$ & $1(14.3)$ & 0.462 & 0.098 \\
\hline
\end{tabular}

The results are presented in groups based on performance level in climbing in the last 6 months (number of climbers $\mathrm{n}$ and \%). 
may have climbed more indoors due to the cold weather. Since seasonal climbers and the outdoor climbers often use indoor climbing in winter as a period of harder training, this may have had an impact on injury rates during the last 6 months.

A weakness of the study is the lack of medical examination of the reported injuries. Although the questionnaire specified that the study was about chronic injuries, this does not guarantee that the respondents reported chronic injuries only; some may have reported acute injuries. Furthermore, some of the reported injuries may have been just pain, not actual injuries. When the athlete is asked for their injury history, they may or may not remember if there was a sensation of pain in the affected area over some time, and there is a risk that acute injuries could be reported as chronic injuries.

A weakness of the study, as well as of previous studies on injuries in climbing, is that the subgroup of recreational climbers is small. It is possible that the recreational climbers did not recognise themselves as 'climbers' and therefore declined to respond to the survey. It is also possible that the recreational climbers never got the chance to respond to the survey. The places where the survey was announced were climbing specific webpages, and it is possible that many recreational climbers may never visit these sites. Altogether, the small number of respondents in the recreational group compared with the experienced group may have given a skewed result in favour of the experienced climbers. This might partly explain the high number of injuries reported.

A possible weakness is responding bias; the climbers responding to the survey may be more likely to have sustained an injury than the average climber.

Strengths of the study are the overall number of participants, the wide range of experience among the respondents, the high number of female respondents and the large group of respondents with no injury. Apart from the under-representation of the recreational climbers, the composition of the respondents in this study is probably in line with the climbing community in Norway, both in terms of level of expertise and representation of genders.

Another strength of the study is that it is a national survey and not limited to a city or just a few climbing gyms. Thanks to the support from the Norwegian Climbing Federation and the national climbing media, this survey has respondents from all over Norway, which gives the study a higher level of generalisability.

\section{CONCLUSION}

The results from this study support the view that climbers with a chronic injury are reluctant to seek healthcare for several reasons.

In the present study it is found significant associations between gender, levels of performance, site of injury, time out of training and the use of healthcare. The effect size is large for variables assessing time out of training and site of injury. When assessing further contributions of gender and level of experience, it seems that experience is a strong predictor for not seeking healthcare after an injury. These findings open up the possibility that some of those who do not seek healthcare after self-assessing the injury are underestimating the seriousness of the injury due to lack of confidence in the health professionals' abilities.

Acknowledgements The authors would like to thank Marius Norberg for helping with the design of the questionnaire.

Collaborators Marius Norberg helped designing the questionnaire from wich the data are subtracted.

Contributors GG collected the data and wrote the paper and AS performed the statistical analyses and collaborated on writing the paper.

Funding The authors have not declared a specific grant for this research from any funding agency in the public, commercial or not-for-profit sectors.

Competing interests None declared.

Patient consent for publication Not required.

Ethics approval The survey is approved by the Regional Ethics Committee. Ref $\mathrm{nr}$ 2016/1533.

Provenance and peer review Not commissioned; externally peer reviewed.

Data availability statement Data are available on reasonable request.

Open access This is an open access article distributed in accordance with the Creative Commons Attribution Non Commercial (CC BY-NC 4.0) license, which permits others to distribute, remix, adapt, build upon this work non-commercially, and license their derivative works on different terms, provided the original work is properly cited, appropriate credit is given, any changes made indicated, and the use is non-commercial. See: http://creativecommons.org/licenses/by-nc/4.0/.

\section{REFERENCES}

1. National geographic. The World's Greatest Free-Solo Climber Isn't Interested in Adrenaline. Available: https://www.nationalgeographic. com/adventure/features/adventurers-of-the-year/2018/alex-honnoldrock-climber/ [Accessed 15 Jan 2019].

2. Paterno MV, Taylor-Haas JA, Myer GD, et al. Prevention of overuse sports injuries in the young athlete. Orthop Clin North Am 2013;44:553-64.

3. federation Nc. Statistics. Available: https://klatring.no/statistikk-nkf accessed 11.2-2019

4. Smucny M, Parikh SN, Pandya NK. Consequences of single sport specialization in the pediatric and adolescent athlete. Orthop Clin North Am 2015;46:249-58.

5. Bell DR, Post EG, Biese K, et al. Sport specialization and risk of overuse injuries: a systematic review with meta-analysis. Pediatrics 2018;142.

6. Fournier-Farley C, Lamontagne M, Gendron P, et al. Determinants of return to play after the nonoperative management of hamstring injuries in athletes: a systematic review. Am J Sports Med 2016;44.

7. Forrester JD, Tran K, Tennakoon L, et al. Climbing-Related injury among adults in the United States: 5-year analysis of the National emergency department sample. Wilderness Environ Med 2018;29:425-30.

8. Baoge L, Van Den Steen E, Rimbaut S, et al. Treatment of skeletal muscle injury: a review. ISRN Orthop 2012;2012:1-7.

9. Backe S, Ericson L, Janson S, et al. Rock climbing injury rates and associated risk factors in a general climbing population. Scand $J$ Med Sci Sports 2009;19:850-6.

10. McDonald JW, Henrie AM, Teramoto M, et al. Descriptive epidemiology, medical evaluation, and outcomes of rock climbing injuries. Wilderness Environ Med 2017:28:185-96.

11. Furst-Nichols N, Jones $\mathrm{C}$, Rueckmann E, et al. Healthcare utilization following acute and overuse injuries among outdoor rock climbers. Wilderness Environ Med 2015;26:94-5.

12. Jones G, Schöffl V, Johnson MI. Incidence, diagnosis, and management of injury in sport climbing and Bouldering: a critical review. Curr Sports Med Rep 2018;17:396-401.

13. Hollander K, Baumann A, Zech A, et al. Prospective monitoring of health problems among recreational runners preparing for a half marathon. BMJ Open Sport Exerc Med 2018;4:e000308. 
14. Bahr R. No injuries, but plenty of pain? On the methodology for recording overuse symptoms in sports. Br J Sports Med 2009;43:966-72

15. Anderson R, Hanrahan SJ. Dancing in pain: pain appraisal and coping in dancers. J Dance Med Sci 2008;12:9-16.

16. van Middelkoop M, Bruens $\mathrm{ML}$, Coert $\mathrm{JH}$, et al. Incidence and risk factors for upper extremity climbing injuries in indoor climbers. Int $J$ Sports Med 2015;36:837-42.

17. Pieber K, Angelmaier L, Csapo R, et al. Acute injuries and overuse syndromes in sport climbing and bouldering in Austria: a descriptive epidemiological study. Wien Klin Wochenschr 2012;124:357-62.

18. Chang CY, Torriani M, Huang AJ. Rock climbing injuries: acute and chronic repetitive trauma. Curr Probl Diagn Radiol 2016;45:205-14.

19. Folkl AK. Characterizing the consequences of chronic climbingrelated injury in sport climbers and boulderers. Wilderness Environ Med 2013;24:153-8

20. Jones G, Asghar A, Llewellyn DJ. The epidemiology of rock-climbing injuries. Br J Sports Med 2008;42:773-8.

21. Jones $\mathrm{G}$, Johnson Ml. A critical review of the incidence and risk factors for finger injuries in rock climbing. Curr Sports Med Rep 2016;15:400-9.

22. Grønhaug G, Norberg M. First overview on chronic injuries in sport climbing: proposal for a change in reporting of injuries in climbing. BMJ Open Sport Exerc Med 2016;2:e000083.

23. Gerdes EM, Hafner JW, Aldag JC. Injury patterns and safety practices of rock climbers. The Journal of Trauma: Injury, Infection, and Critical Care 2006;61:1517-25.

24. Logan A, Makwana N, Mason G, et al. Acute injuries in the hand and wrist. Br J of Sports Med 2004;38:545-8.

25. Grønhaug G. Self-reported chronic injuries in climbing: who gets injured when? BMJ Open Sport Exerc Med 2018;4:e000406.

26. Rea L, RA P. Designing and conducting survey research a comprehensive guide. 4 ed. San Fransisco: Jossey-Bass, 2014.
27. Schöffl VR, Schöffl I. Finger pain in rock climbers: reaching the right differential diagnosis and therapy. J Sports Med Phys Fitness 2007;47:70-8.

28. Hughes CM, McElnay JC, Fleming GF. Benefits and risks of self medication. Drug Saf 2001;24:1027-37.

29. Rose MS, Emery CA, Meeuwisse WH. Sociodemographic predictors of Sport injury in adolescents. Med Sci Sports Exerc 2008;40:444-50.

30. Piper KF, Gold JR, Bodkin RP, et al. Rock climbers' management of hand injuries and perceptions on seeking healthcare: A mixed methods analysis. Cogent Med 2017;4.

31. Buda R, Di Caprio F, Bedetti L, et al. Foot overuse diseases in rock climbing: an epidemiologic study. J Am Podiatr Med Assoc 2013;103:113-20.

32. Green CA, Pope CR. Gender, psychosocial factors and the use of medical services: a longitudinal analysis. Soc Sci Med 1999;48:1363-72.

33. Bertakis KD, Azari R, Helms LJ, et al. Gender differences in the utilization of health care services. J Fam Pract 2000;49:147-52.

34. Grønhaug G. Adressing the elephant in the room: a possible new way to increase patient adherence to medical advice. Patient preference and adherence 2017;28:1083-9.

35. Desaldeleer A-S, Le Nen D. Bilateral fracture of the base of the middle phalanx in a climber: literature review and a case report. Orthopaedics \& Traumatology: Surgery \& Research 2016;102:409-11.

36. Arnold A, Thigpen CA, Beattie PF, et al. Overuse physeal injuries in youth athletes. Sports Health 2017;9:139-47.

37. Bojoly K, Moutet F. Prévention des lésions des cartilages de croissance des doigts CheZ les jeunes grimpeurs. Journal de Traumatologie du Sport 2018;35:4-14. 